\title{
Article
}

\section{Additive manufacturing of a point-of-care "polypill": Fabrication of concept capsules of complex geometry with bespoke release against cardiovascular disease}

Pereira, Beatriz, Isreb, Abdullah, Isreb, Mohammad, Forbes, Robert Thomas, Oga, Enoche Florence and Alhnan, Mohamed

Available at http://clok.uclan.ac.uk/33324/

Pereira, Beatriz, Isreb, Abdullah, Isreb, Mohammad, Forbes, Robert Thomas ORCID: 0000-0003-3521-4386, Oga, Enoche Florence ORCID: 0000-00022661-0574 and Alhnan, Mohamed (2020) Additive manufacturing of a pointof-care "polypill": Fabrication of concept capsules of complex geometry with bespoke release against cardiovascular disease. Advanced Healthcare Materials, 9 (13). ISSN 2192-2640

It is advisable to refer to the publisher's version if you intend to cite from the work. http://dx.doi.org/10.1002/adhm.202000236

For more information about UCLan's research in this area go to http://www.uclan.ac.uk/researchgroups/ and search for <name of research Group>.

For information about Research generally at UCLan please go to http://www.uclan.ac.uk/research/

All outputs in CLoK are protected by Intellectual Property Rights law, including Copyright law. Copyright, IPR and Moral Rights for the works on this site are retained by the individual authors and/or other copyright owners. Terms and conditions for use of this material are defined in the policies page. 
2 Additive manufacturing of a point-of-care

3 "polypill": Fabrication of concept capsules of

4 complex geometry with bespoke release against

5 cardiovascular disease

6

7 Beatriz C. Pereira, Abdullah Isreb, Mohammad Isreb, Robert T. Forbes, Enoche F. Oga*,

8 Mohamed A. Alhnan**

9

10

11

12

13

14

15

16

17

18

B. C. Pereira, Dr. A. Isreb, Prof. R. T. Forbes, *Dr. E. F. Oga,

School of Pharmacy \& Biomedical Sciences

University of Central Lancashire

Fylde road, PR1 2HE, UK

E-mail: EOga@uclan.ac.uk

**Dr M. A. Alhnan

Institute of Pharmaceutical Sciences

King's College London

5.77 Franklin Wilkins Building, 150 Stamford Street, SE1 9NH, UK

E-mail: alhnan@kcl.ac.uk

Keywords: multidrug, fixed dose combination (FDC), digital health, computer-aided design (CAD), controlled-release, in vitro-in vivo correlation 
Abstract

Polypharmacy is often needed for the management of cardiovascular diseases and is associated with poor adherence to treatment. Hence, highly flexible and adaptable systems are in high demand to accommodate complex therapeutic regimens. A novel design approach was employed to fabricate highly modular 3D printed 'polypill' capsules with bespoke release patterns for multiple drugs. Complex structures were devised using combined fused deposition modelling 3D printing aligned with hotfilling syringes. Two unibody highly modular capsule skeletons with 4 separate compartments were devised: i) concentric format: two external compartments for early release whilst two inner compartments for delayed release, or ii) parallel format: where non-dissolving capsule shells with free-pass corridors and dissolution rate-limiting pores were used to achieve immediate and extended drug releases, respectively. Controlling drug release was achieved through digital manipulation of shell thickness in the concentric format or the size of the rate limiting pores in the parallel format. Target drug release profiles were achieved with variable orders and configurations, hence confirming the modular nature with capacity to accommodate therapeutics of different properties. Projection of the pharmacokinetic profile of this digital system capsules revealed how the developed approach could be applied in dose individualization and achieving multiple desired pharmacokinetic profiles. 


\section{Introduction}

Population-based surveys and cross-sectional studies have shown that polypharmacy affects 40$50 \%$ of elderly patients in high income countries. ${ }^{[1-3]}$ Among chronic conditions, cardiovascular disease (CVD) accounts for $45 \%$ of all deaths in Europe ${ }^{[4]}$ and its management necessitates a complex therapeutic regimen, which usually includes anti-platelet, anti-hypertensive and lipidlowering agents. ${ }^{[5]}$ Such complex treatment has been linked to many issues, including psychological distress, depressing symptoms and poor adherence among patients. ${ }^{[6-8]}$ Common strategies to improve patient compliance include the use of medication boxes or technologies like PillPack dispensing system, alarms to remember dose times, medicines administration records (MARS), and smartphone applications such as My Medication Passport. ${ }^{[9-11]}$

However, these approaches are usually associated with instructions that may be hard-to-read, understand and/or even follow by elderly patients. ${ }^{[12]}$ Additionally, daily medication boxes often contain different unlabelled tablets/capsules that may have similar physical appearance and might lead to dispensing, patients or carers errors. Therefore, technology-based approaches need a more rigorous evaluation of cost-effectiveness and patient acceptability, suggesting that a more simplified and efficient strategy is needed. ${ }^{[13]}$ Polypills can simplify the dosing regimen without compromising the therapeutic plan. The rapidly growing interest in this approach resulted in the progression of several combinations of drugs to clinical trials and registered products. ${ }^{[14]}$ Despite their proven advantages, the rigid nature of fixed multiple-drug combination in a single pill may be suitable for a limited number of patients. Hence, a highly adaptable manufacturing technique that allows easy selection and titration of multiple drug doses is needed.

$3 \mathrm{D}$ printing is an emerging production method with potential superior agility in the production of on-demand medicines, with a small number of processing steps, low costs and flexibility of design. ${ }^{[15,16]}$ Several studies have reported the applicability of fused deposition modelling (FDM) $3 \mathrm{D}$ printing in the production of solid dosage forms. ${ }^{[17-19]}$ Its advantage of medicine personalization has been extensively explored, in special patient groups (e.g. paediatrics), by 
improving characteristics such as palatability, ${ }^{[20]}$ and by fabrication of a 'dynamic dose combiner' which can be easily shaped to each patient's needs. ${ }^{[21,22]}$

To optimise therapeutic effect, controlling drug release from 3D printing technologies was achieved by modifying printing parameters e.g. infill percentage, ${ }^{[23,24]}$ or the shape or size of the dosage form. ${ }^{[25]} 3 \mathrm{D}$ printed capsules avoid the high temperatures usually required with FDM 3D printing. An early attempt of FDM 3D printing of a pulsatile release capsule system was reported in $2015 .{ }^{[26]}$ Further studies have achieved delayed ${ }^{[27,28]}$ or pulsatile release capsules. ${ }^{[29]}$ The capsules were manufactured in two pieces to be manually assembled in a second step. Therefore, a one-step 'print and fill' capsule was developed. ${ }^{[30,31]}$ However, the use of water-based formulations was linked to moisture absorption by Polyvinyl(alcohol) (PVA) shells with swelling, wall delamination and leakage of the infill. Such deficiencies highlighted the need for formulation optimization of a capsule filling that was compatible with the polymeric walls. Also desirable, and explored in the current study, is a 3D printable modular system capable of including larger numbers of molecules and controlling their dissolution rate.

Physiologically based pharmacokinetic (PBPK) model simulation is a tool which has been increasingly used in pharmaceutical development in order to improve efficiency and reduce costs in drug development and absorption, distribution, metabolism \& excretion (ADME) assessments. It has proved useful in optimization of clinical trials design, for example in the selection of the drug dose, and helped to understand how individual variability affects drug pharmacokinetics. The simulation model has also demonstrated to be a valuable tool in clinical trials that need individualized adjustable drug doses, for example paediatric ${ }^{[32]}$ and hepatically impaired patients. ${ }^{[33]}$

In this study, we present a facile modular platform for individualized complex therapeutic regimens. By adopting combined hot-fill technology to produce unibody capsules of complex structure, a highly modular capsule platform with tuneable release was achieved by mere use of a modified digital design. Four model drugs were used in the development of two highly flexible systems. The first system was based on manipulating pore size in a water insoluble biodegradable 
shell (polylactic acid (PLA)). The second system was based on shell thickness control of a water soluble PVA shell. The in-silico simulation of pharmacokinetics of these tablets aimed to provide a means of pre-designing optimization of the pharmacokinetics of multiple drugs to suit individual patient need.

\section{Results and discussion}

Capsules of complex structure were designed to include an oval hollow geometry comprising 4 compartments, where each compartment accommodated a single drug-loaded capsule filling. The compartments were configured in two design formats (parallel or concentric) to achieve different drug release patterns. Each design was split into two complementary parts: top and bottom design files (correspondent to the base and cap) (Figure 1). The design allowed for three-step manufacturing, where the base of the capsules was produced first (Figure 2A3 and 2B3), then hot-filled (Figures 2A4 and 2B4) before, thirdly, a complementary cap is printed with subsequent sealing of the capsule (Figure 2A5 and 2B5). After dispensing the identical volume of the filling, it reached similar height within the capsule. The physical isolation of each drug in a separate compartment is considered to prevent potential drug-drug interactions within the dosage form and allow for the individualization and "tuning" of each model drug's release profile.

Parallel compartments were designed into the capsular structure with different pore sizes, according to the desired release profile (Figure 1A). Internal compartments were designed with (2 mm) free-pass windows to yield an immediate release profile whilst external compartments were fabricated with rate-limiting pores to extend drug release from the capsule. Following an optimization process of pore configuration, dual pores for each side of the compartment seem to allow faster drug release than a single pore of double size (Supporting information, Figure S1). The impact of pore size on drug release was also screened for all module drugs (Supporting information, Figure S2). Finally, total pore surface areas of $0.25 \mathrm{~mm}^{2}$ and $0.49 \mathrm{~mm}^{2}$ for each compartment were selected to offer an extended release (Figure 1B4). The inclusion of four identical square-shaped pores with a total area of $0.25 \mathrm{~mm}^{2}$ and $0.49 \mathrm{~mm}^{2}$ for each compartment 
125 permitted aqueous flow within the capsule. SEM images confirmed pore walls within a range of

$126 \pm 60 \mu \mathrm{m}$ of the design (data not shown).

127 To obtain extended and delayed drug release profiles, an alternative format (concentric capsule)

128 was devised. Two external and two internal compartments were configured to obtain extended and delayed drug release profiles, respectively (Figure 1B). A wall thickness of $0.6 \mathrm{~mm}$ was selected to maintain physical integrity of the capsule. By manipulating the thickness of the bottom, upper and inner walls of the two inner compartments, the design aimed to control the lag time of the delayed drug release. Capsules of different thickness of the inner wall (in multiple increments of $0.6 \mathrm{~mm}$ ) were fabricated to probe their effectiveness in delaying drug release

(Figures 2A1/2/6).

In order to establish the modularity of the system to meet various patients' needs, both design formats were configured in two drug-sequences: Sequence I, where the most soluble drugs (lisinopril and amlodipine) are dispensed in the immediate (PLA shell) or extended (PVA shell) release compartment and the least soluble drugs (indapamide and rosuvastatin) were placed in the extended (PLA shell) or delayed (PVA shell) release compartments. Sequence II differed in that the model drugs were configured in reverse order.

Liquid infill formulations are often used in capsules to improve solubility or the dissolution of poorly soluble drugs. ${ }^{[34]}$ Putting a liquid formulation into a 3D printed capsule shell presents a major challenge with reported leaking issues and loss of capsule structure. ${ }^{[31]}$ To establish compatibility between the infill versus the PVA and PLA 3D printed capsule shells, a fluorescent molecule was used in the hot fill process of a liquid formulation of PEG 400, a commonly used solubility enhancer in soft gelatine capsules. ${ }^{[35,36]}$ Photographs of PVA concentric capsules showed the absorption of the PEG solution by the shell through time (Figure 3A). Indeed, microscopic pictures confirmed the migration of fluorescent solution through the polymeric shell in contact with the PEG solution. This could be attributed to the established miscibility of PEG 400 with the PVA matrix $\cdot{ }^{[37]}$ Likely arising from the significant known plasticising effect of PEG 
this could lead to interference of the different drug-loaded fillings and alter the individualized release patterns of the drugs as well as initiating potential drug-drug interactions. On the other hand, PLA capsules remained visibly unchanged with PEG solution as the capsule filling (Figure 3B). However, a previous study has reported the plasticising effect of PEG 400 in PLA when mixed at $90{ }^{\circ} \mathrm{C} .{ }^{[39]}$

To overcome this, PEG 4000 (melting temperature of $61.5^{\circ} \mathrm{C}$,) was added to allow solidification of the structure at room temperature (Figures $4 \mathbf{E} / \mathbf{F} / \mathbf{G} / \mathbf{H})$. The paste was engineered to solidify rapidly within the capsule compartments. Our initial screening indicated that an overall percentage of PEG blends is ideal around $40 \%$ to maintain the integrity of the shell e.g. an increased ratio of PEG 400 yielded fillings that leaked and were not compatible with the shell, while fillings with increased ratio of PEG 4000 were too slow to solidify and compromised the shell integrity (data not shown). In order to regulate the rheological behaviour during extrusion, lactose was added to the blend and yielding a facile filling paste to be hot-filled at relatively low temperature $\left(60{ }^{\circ} \mathrm{C}\right)$. Thermogravimetric analysis was performed in order to assess thermal stability of the raw materials and the developed drug-loaded capsule fillings. Thermogravimetric profiles of drug-loaded capsule fillings showed continuous weight loss of about $3 \%$ up to $120^{\circ} \mathrm{C}$, which was believed to be due to evaporation of moisture in the PEG 400, PEG 4000 and drug substance (Figure $4 \mathbf{A} / \mathbf{B} / \mathbf{C} / \mathbf{D}$ ). No significant weight loss was observed at the processing temperature $\left(60^{\circ} \mathrm{C}\right)$.

The stability of the drug in the fill matrix was determined after 24 hrs to assess the compatibility of the model drugs at the processing conditions temperature. All individual capsule fillings showed a good stability at the processing temperatures for a period of at least $24 \mathrm{hrs}$ (data not shown), a finding indicating that the composition would be compatible with a process automation using dispensing heated syringes.

Considering the results of differential scanning calorimetry, the presence of the endothermic peaks corresponding to the melting of a blend of PEG 400, PEG 4000 and lactose for the drugfree and drug-loaded capsule fillings, confirms the presence of crystalline components, which 
facilitates their solidification on dispensing to the capsule shell. A broad peak is seen in both drugfree and drug-loaded capsule fillings in the range of $100-150{ }^{\circ} \mathrm{C}$, that may be explained by dehydration of lactose (Figure 4). The DSC profile for the lisinopril-loaded capsule filling suggested degradation at around $150{ }^{\circ} \mathrm{C}$. This finding was not unexpected given the reported sensitivity of this molecule to degradation through a Maillard reaction with lactose (Figure 4E). [40] The use of $60{ }^{\circ} \mathrm{C}$ as a processing temperature will minimise the interaction.

XRD intensity patterns of the lisinopril-loaded capsule filling showed diffraction peaks characteristic of the drug substance at $2(\Theta)=7.5^{\circ}, 12.5^{\circ}$ and $13.6^{\circ}$, revealing the presence of the crystalline form of the drug (Figure 5A). The absence of characteristic diffraction peaks of amlodipine, indapamide and rosuvastatin in their correspondent capsule filling indicates that these drug substances were likely amorphous within capsule fill matrices (Figures 5B-D). This finding was consistent with DSC data, which revealed no endothermic events near the melting temperatures of any of the drugs. These findings could be partially explained by the solubility parameters values of PEG and the model drugs (Table 2). Lisinopril and amlodipine showed the highest discrepancy in total solubility parameter value in comparison to PEG, while rosuvastatin and indapamide have solubility parameter values with a difference of $<7 \mathrm{MPa}^{1 / 2}$.

While PEG 400 serves as solvent, PEG 4000 and lactose were added to increase the viscosity of infill upon cooling to room temperature. Therefore, rheology studies were performed to confirm the functionality of PEG 4000 and lactose in the capsule fillings as viscosity enhancers. This will allow to assess the flowability of the filling at various temperatures and identify the ideal temperature for capsule filling. The viscosity of the filling was assessed at various temperatures. Complex viscosity data at the processing temperature $\left(50^{\circ} \mathrm{C}\right)$ are shown in Figure 5E. (Attempts to assess the complex viscosity of the samples at room temperature $\left(25^{\circ} \mathrm{C}\right)$ were unsuccessful, due to the solid nature of the ink). The minimum temperature that allowed successful analysis was $40{ }^{\circ} \mathrm{C}$ and results can be seen in Figure 5F. The results show that PEG 400 has a relatively low viscosity with minimum shear thinning behaviour (typical Newtonian fluid). On the other hand, PEG 4000 has the highest complex viscosity value with a more pronounced shear thinning 
behaviour typical of thermoplastic polymers. Their mixtures exhibited a complex value in between both the pure material with shear thinning behaviour. The addition of lactose increased the complex viscosity value while maintaining the shear-thinning behaviour. In general, adding model drugs to each formulation did not have a significant effect on the complex viscosity (complex viscosity studies for other model drugs are shown in Supporting information, Figure S3).

The strategy of pore fabrication via FDM 3D printing can influence drug release profiles. Initially, drug release from the capsule was attempted through inclusion of a single perforating square shape (pore), however drug release was limited. To accelerate drug release, a dual pore system was employed for each compartment. The effect on drug release was markedly evident compared to a single pore, despite having the same total area (Supporting information, Figure S1). The increase was attributed to an enhanced hydrodynamic flow through the capsule in the dual pore system, leading to accelerated media flow and a thinner dissolution layer. It is also possible that air bubbles can be entrapped within the compartment and hinder hydrodynamic flow within the compartment. Therefore, this risk was mitigated by using four rate-limiting pores per compartment.

Different pore areas were then evaluated (Supporting information, Figure S2). In general, an increase in the total area pore area resulted in faster release rate of the drugs. However, controlling release by modification of the pores area proved to be more effective with indapamide and rosuvastatin, which have lower aqueous solubilities, when compared with lisinopril and amlodipine. ${ }^{[1-44]}$ Total areas of 0.25 and $0.49 \mathrm{~mm}^{2}$ provided a better extended release for lisinopril and amlodipine, and indapamide and rosuvastatin, respectively. In Sequence I, lisinopril and amlodipine showed an immediate release with $>80 \%$ of drug dissolved in $30 \mathrm{~min}$. A total pore area of $0.49 \mathrm{~mm}^{2}$ was necessary to achieve $89 \%$ and $55 \%$ of indapamide and rosuvastatin release after 24 hrs (Figure 6A2). The effect of drug solubility was visually demonstrated by comparing with Sequence II, where the free-pass corridors allowed $>80 \%$ of indapamide release only after 3 hours (Figure 6B). An increase in the dissolution rate after $\mathrm{pH}$ change at $2 \mathrm{hrs}$ was observed for 
rosuvastatin and indapamide which can be explained by their acidic nature (pKa of 4.2-4.6 and 8.8 respectively). ${ }^{[45,46]}$ Although a $0.49 \mathrm{~mm}^{2}$ area proved to be suitable to reach extended release in Sequence I, a smaller area (of $0.25 \mathrm{~mm}^{2}$ ) was necessary to slow down lisinopril and amlodipine release (Figure 6B1). This illustrated the importance of software input to "tune" drug release through pore size to accommodate a wide range of model drugs of variable solubilities. Incomplete drug release was observed for indapamide and rosuvastatin in Figures 6A1/A2 and for lisinopril and indapamide in Figure 6B1, after a period of $24 \mathrm{hrs}$. This might lead to higher plasma exposure when patients have longer transit time.[47] Therefore, it is important to engineer capsules to complete drug release within the transit time of non-disintegrating oral doses.

In order to achieve a chronotherapeutic effect, a concentric PVA polymeric shell was devised. The design was successful in producing extended and time-dependent delayed release (Figure 7). In general, a thickness of $0.6 \mathrm{~mm}$ was responsible for a lag time of $1 \mathrm{hr}$, and drugs dispensed in the external compartments achieved $>75 \%$ of drug released after approximately 3 hours after the start of dissolution (Figure 7). This lag phase can be attributed to the time needed for the dissolution of the outer shell and drugs in the external compartments. The dissolution mechanism of PVA in the capsule shell is mediated mainly through erosion. ${ }^{[48,49]}$ Increasing the inner, top and bottom walls thicknesses to $1.2,1.8$ and $2.4 \mathrm{~mm}$ resulted in a lag time of $\sim 4,6$ and $8 \mathrm{hrs}$, respectively, and $>80 \%$ drug dissolution around 6 hrs thereafter (Figure 7A3/B3). External compartments (of $0.6 \mathrm{~mm}$ thickness) eroded at a speed of $0.6 \pm 0.0 \mathrm{~mm} / \mathrm{hr}$, and internal compartments at $0.41 \pm 0.09 \mathrm{~mm} / \mathrm{hr}$. The suitability of the polypills was demonstrated using four clinically relevant drugs for the treatment of CVD, however its application to other therapeutic regimens is unlimited. The high versatility of the system is expected to be associated with improved clinical outcomes, by customization of the release profile of drugs to target specific times to attain peak plasma concentration and to avoid drug-drug interactions in complex therapies. One limitation of the developed capsule systems is its relatively large size and shape. Further reduction of the capsules size and a transformation to capsule-like geometry could be 
applied to meet FDA guidance for recommended size and shape in order to improve patient acceptability. ${ }^{[50]}$

In the clinical setting, bespoke dosage forms can be dispensed as a patient-specific medicine in an extemporaneous setting. Initial stability trials to determine the impact of storage conditions of the developed capsules were conducted over 28 days. In general, no physical change of the capsule structure was observed by visible inspection (Supporting information, Figure S4). Lisinopril and rosuvastatin did not show significant $(\mathrm{p}>0.05)$ degradation when stored at $4^{\circ} \mathrm{C}$ (Supporting information, Table S1), while a decrease in drug content was significant ( $p>0.05$ ) for indapamide and amlodipine when in PLA capsules. This may be explained by a protective effect of the PVA shell on moisture. The highest degree of degradation of amlodipine when compared with the rest of the model drugs may be due to the high sensitivity of this drug molecule to moisture and light. ${ }^{[51,52]}$ It is possible that the open pores within the architecture of the parallel design favoured the penetration of light and moisture and contributed to higher level of degradation in amlodipine chamber. In general, immediate release chambers yielded similar release pattern, whilst extended and delayed release patterns was more sensitive to storage temperature (Supporting information, Figures S5 and S6).

To project the clinical implication of using this bespoke drug delivery system for cardiovascular system, a simulation absorption model was developed to study the effect of drug dissolution in drug pharmacokinetics. Validation of the developed models was performed by comparison of the simulated AUC, $\mathrm{C}_{\max }$ and $\mathrm{T}_{\max }$ with the observed clinical studies (Supporting information, Table S2). PLA-based capsules showed a clear predictable effect of drug dissolution in the pharmacokinetics profile. $\mathrm{C}_{\max }$ was proportional with the maximum drug release achieved from the in vitro dissolution studies (Figure 8 and Supporting information, Figures S7). PVA-based concentric capsules with different wall thicknesses showed similar good correlation with $\mathrm{C}_{\max }$ values and $\mathrm{T}_{\max }$ values proportionally increasing with the drug release time (Figure 9 and Supporting information, Figures S8). Pharmacokinetic parameters values obtained for PLA and PVA capsule systems can be found in Supporting information, Table S3 
and S4, respectively. The ease of modelling the results highlights the applicability of such a highly modular drug delivery systems to conveniently produced timed drug dose release with "tuned" peak drug plasma concentrations to achieve optimal clinical outcome.

We envisage the employment of such digitised and modular system as part in an integrated healthcare network in the future (Figure 10). In such a configuration, patient's data and genomics will feed an artificial intelligent and big data-powered network, where desired target PK profile can be set, tested and refined in multiple cycles to achieve clinical outcome in seamless fashion. The growth of database and number of participants in such integrated system to a critical mass can potentially revolutionise and transform the efficacy, safety and patient-centricity of multiple drug treatments.

\section{Conclusions}

We present a highly modular multi-compartmental capsule platform of complex structure that accommodates 4 model drugs for bespoke dosing and drug release. A specially developed rapid solidifying fill matrix proved compatible with two biodegradable polymeric shells (PVA and PLA). Two architecture formats, based on digital manipulation of wall thickness and pore sizes, allow a customised release profile for each drug molecule. The novelty of this system resides in employing an established additive manufacturing method with liquid dispensing to achieve a complex multidrug releasing dosage form starting from identical materials. Hence, the platform enables serving large number of patients with a small number of starting materials and relatively low costs. The approach yields minimal migration of the formulation through the shell structure and is stable for 28 days following production (comparable to the usual shelf-life for extemporaneous preparations). While this work provides a proof-of-concept for 4 drug molecules, the reported platform can easily be generalised to a wider spectrum of drug substances that are frequently prescribed together. This work showcases a powerful and economical approach of digital design to provide healthcare staff with a highly adjustable 'polypill' solution, to 
311 accommodate the increasing number of patients who receive multiple and complex dosing

312 regimens.

\section{Experimental Section}

314

315

Materials: Lisinopril dihydrate, amlodipine besylate, indapamide and rosuvastatin calcium were obtained from Kemprotec Ltd (Cumbria, UK). HPLC gradient grade acetonitrile and methanol were from Fisher Scientific Ltd (Loughborough, UK). Dipyridamole, poly(ethylene glycol) (PEG) 4000 and alpha-D-Lactose monohydrate ACS reagent grade were purchased from Thermo-Fisher Scientific (UK). Poly(ethylene glycol) (PEG) 400 was from Merck KGaA (Darmstadt, Germany). Polyvinyl alcohol (PVA) and Poly(lactic acid) (PLA) filaments were obtained from MakerBot ${ }^{\circledR}$ Industries (NY, USA). All other chemicals were of analytical grade.

Preparation of the capsule fill matrix: A rapid solidifying shell-compatible hot-fill fluid was developed. The composition of each drug-loaded fill matrix is detailed in Table 1. The filling was prepared by dissolving accurately weighed model drug in PEG 400 in a beaker and sonicating the solution/suspension for $15 \mathrm{~min}$. PEG 4000 was then incorporated in the mixture, which was then heated in a FD240 binder heating chamber (Tuttlingen, Germany) for $1 \mathrm{hr}$ at $60^{\circ} \mathrm{C}$. Following the complete melting of PEG 4000 and mixed, lactose was suspended and manually mixed to obtain a uniform paste. Pastes were then maintained at $50^{\circ} \mathrm{C}$. A volume of $80 \mu \mathrm{L}(\sim 100 \mathrm{mg})$ of each model drug fill matrix was manually dispensed in each capsule compartment using a 1-mL GASTIGHT $^{\circledast}$ syringe (Hamilton Company, UK) equipped with a 18 gauge- $6.35 \mathrm{~mm}$ length needle (McMaster-Carr, CA, USA).

$3 D$ printing of capsules: Capsule shells of innovative complex architecture were designed using Autodesk $^{\circledR}$ 3ds Max Design 2016 software version 18.0 (Autodesk, Inc., USA). An oval shape was chosen to simplify its division into 4 compartments with similar volumes. The capsules (with $0.6 \mathrm{~mm}$ walls $)$ were designed with a standard size of $24.1 \times 15.1 \times 6.26(\mathrm{X} \times \mathrm{Y} \times \mathrm{Z}) \mathrm{mm}$. PVA 
capsules were designed with $\mathrm{z}$ dimension of $7.46,8.66$ and $9.86 \mathrm{~mm}$ for designs with inner wall thickness of 1.2, 1.8 and $2.4 \mathrm{~mm}$ respectively. Two design formats (Figure 1) were adopted to couple extended or delayed release patterns for two model drugs with immediate or extended release for the other two model drugs:

1. PLA-based parallel design capsules with immediate release and extended release architecture (Figure 1A). Internal compartments were designed with free-pass corridors $(2 \mathrm{~mm})$ to facilitate free access of dissolution media and subsequent rapid dissolution and release of capsule fillings. External compartments were designed with rate-limiting pores. The optimization of the design was performed by assessing the release profile of the drugs using a different number (two or four) of the rate-limiting pores per compartment and different total pore areas (namely, $0.25,0.49,0.72$ and $1 \mathrm{~mm}^{2}$ ). After optimization, the design with four pores per external compartment (two on each side) and pores areas of 0.25 and $0.49 \mathrm{~mm}^{2}$ were selected as a default.

2. PVA-based concentric design capsules with variable shell thicknesses (Figure 1B) with extended and delayed release system architecture. External walls of the capsule were designed with a 0.6-mm thickness to provide an extended release. Capsules with top, bottom and internal walls were designed with various wall thicknesses (namely $0.6,1.2$, 1.8 or $2.4 \mathrm{~mm}$ ) in order to achieve a delayed drug release profile from the internal compartments.

Each design was split into two complementary objects: cap and base. 3D printing of both capsule formats was done using a Makerbot Replicator 2X (Makerbot Industries, LLC, USA) at nozzle and platform temperatures of $200{ }^{\circ} \mathrm{C}$ and $50{ }^{\circ} \mathrm{C}$, respectively. Capsule shells were divided in two stereolithography (.stl) files format correspondent to the base and cap of the capsule. 3D printing of the capsule shells was performed without using removable supports and took a maximum of 10 min. Each capsule was fabricated in three steps: i) 3D printing of the bottom portion of the design (base), ii) manual capsule filling as detailed in the previous section, and iii) 3D printing of complementary top part (cap). The printing of cap was set using the identical $x-y$ position on the 
364

printing plate and at z-level equivalent to the height of the complementary base. No additional sealing materials or process were used in the process.

Compatibility of the hot-filling matrix with the capsule shell: Fill-matrix compatibility with PLA and PVA shells was studied by assessing the developed fast solidifying fills using a fluorescent molecule (dipyridamole). Capsule fillings (as described above) and dipyridamole solution in PEG 400 (control) were dispensed in PLA and PVA capsules and visualised in a NOVEX B-range microscope after $0,0.5,2$ and 24 hrs. Samples were prepared using the concentration correspondent to the model drug with lowest dose (indapamide), $31.25 \mathrm{mg} / \mathrm{mL}$ and $2.5 \%$ for the PEG 400 and capsule filling samples, respectively. The capsules were kept at room temperature throughout the experiment and images were obtained using Image focus v3.0.0.1 software to visualise integrity.

High performance liquid chromatography (HPLC): Drug content and dissolution tests samples were analysed by HPLC, using a method that has been described in a previous study. ${ }^{[53]}$

Thermal analysis: Thermogravimetric analysis (TGA) analysis was performed on a TGA Q500 (TA Instruments, Elstree, Hertfordshire, UK) and samples of the raw materials and the capsule fill matrix were run in triplicate. Each sample (approximately $10 \mathrm{mg}$ ) was heated at a rate of $10^{\circ} \mathrm{C} / \mathrm{min}$ from 25 to $500^{\circ} \mathrm{C}$ with a nitrogen purge of $40: 60 \mathrm{~mL} / \mathrm{min}$ for sample: furnace respectively. Differential Scanning Calorimetry (DSC) analysis was conducted on a DSC Q2000 (TA Instruments, Elstree, UK). Samples ( $10 \mathrm{mg})$ of the raw materials and the capsule fill matrix were analysed in triplicate using T-zero hermetic pans. Each sample was scanned from -50 to $230{ }^{\circ} \mathrm{C}$ at $10{ }^{\circ} \mathrm{C} / \mathrm{min}$ using a nitrogen purge of $50 \mathrm{~mL} / \mathrm{min}$. Data obtained from both TGA and DSC were analysed with TA Universal analysis software v4.5A (TA Instruments, Elstree, UK).

Powder X-ray diffractometry $(X R D)$ : Powder XRD analysis of the raw materials and capsule filling was carried out using an X-ray diffractometer, D2 Phaser with Lynxeye (Bruker, Germany). Each sample was scanned from $2 \Theta=5^{\circ}$ to $50^{\circ}$ with a $0.01^{\circ}$ step width and a $1.25 \mathrm{sec}$ 
time count. The divergence slit and scatter slit were $1 \mathrm{~mm}$ and $0.6 \mathrm{~mm}$, respectively. The wavelength of the $\mathrm{X}$-ray was $0.154 \mathrm{~nm}$ using a $\mathrm{Cu}$ source, a voltage of $30 \mathrm{kV}$ and a filament emission of $10 \mathrm{~mA}$.

Rheological studies of the capsule fill matrix: Rheology studies were performed on the capsule fills using an Anton Paar Shear Rheometry Physica MCR 301 (Graz, Austria) with 25mm parallel plates, using a $0.5 \mathrm{~mm}$ gap distance in oscillation mode. Linear viscoelastic region (LVR) was studied with $0.5 \%$ strain amplitude. Samples were tested in triplicate using an amplitude sweep at an angular frequency range from 0.1 to $100 \mathrm{rad} / \mathrm{s}$ and angular frequency of $10 \mathrm{rad} / \mathrm{s}$. Temperatures were set at 40 and $50^{\circ} \mathrm{C}$ (dispensing temperature) and readings were collected every $5 \mathrm{sec}$.

Solubility parameter: Hansen solubility parameters were calculated using HSPiP v5.0.08 software. The canonical simplified molecular-input line-entry system (SMILES) of the compounds as stated in ${ }^{[54]}$ was used to calculate the solubility parameters using group contribution method. It is worth noting that PEG 400 and PEG 4000 have identical SMILES and therefore have identical solubility parameter values.

Stability assessment: The stability of the developed formulation was assessed in terms of compatibility with the capsule shells, drug content and dissolution profile. The drug content (w/w\%) of each capsule filling was calculated by comparing the recovered amount with the theorical amount.

a. Stability at processing conditions: To mimic the impact of the temperature of capsule filling on model drug integrity, drug contents of capsule fill pastes (stored in syringe) were assessed at $50{ }^{\circ} \mathrm{C}$ in a FD240 Binder heating chamber (Tuttlingen, Germany). Samples were collected at the time points 0 and $24 \mathrm{hrs}$, filtered through an Econofltr 0.2 $\mu \mathrm{m}$ syringe filter (Agilent Technologies Ltd., Cheadle, UK) and analysed in triplicate by the HPLC method mentioned above. ${ }^{[53]}$ 
b. Accelerated stability study: Accelerated stability of the 3D printed capsules (Sequence I PLA-based capsules with $0.49 \mathrm{~mm}^{2}$ pores and Sequence I PVA-based capsules with 1.8 mm wall thickness) was performed according to ICH guidelines for one month, at $4{ }^{\circ} \mathrm{C}$, $30{ }^{\circ} \mathrm{C} / 65 \% \mathrm{RH}$ and $40{ }^{\circ} \mathrm{C} / 75 \% \mathrm{RH}$. Capsules were individually stored in high-density polyethylene bottles and analysed in triplicate in terms of visual assessment of physical capsule structure, drug content and dissolution profile (see above). For drug content analysis, PVA capsules were placed in $800 \mathrm{~mL}$ of water and sonicated until complete dissolution, followed by the addition of $200 \mathrm{~mL}$ of acetonitrile and further sonication for $1 \mathrm{hr}$. PLA capsules were firstly dissolved in $200 \mathrm{~mL}$ of acetonitrile followed addition of $800 \mathrm{~mL}$ water and sonication for $1 \mathrm{hr}$. For amlodipine analysis, $1 \mathrm{~mm}$ EDTA was added the solution. The solutions were then filtered through an Econofltr $0.2 \mu \mathrm{m}$ syringe filter (Agilent Technologies Ltd., Cheadle, UK) and analysed by HPLC as described above.

Scanning electronic microscopy (SEM) The thickness of the inner wall of the PVA concentric capsules and the pores of the PLA capsules were analysed with a JCM-6000 plus NeoScope ${ }^{\mathrm{TM}}$ microscope (Jeol, Tokyo, Japan) at $10 \mathrm{kV}$. Prior to imaging, samples were gold coated under vacuum for 2 min with a JFC-1200 Fine Coater (Jeol, Tokyo, Japan).

In vitro dissolution tests. The dissolution tests for 3D printed capsules were performed on an Erweka DT600 USPII dissolution test apparatus (Heusenstamm, Germany). The tests were run at $37^{\circ} \mathrm{C}$ with a paddle rotation speed of $50 \mathrm{rpm}$, under sink conditions. The capsules were tested in $750 \mathrm{~mL}$ of $0.1 \mathrm{M} \mathrm{HCl}(\mathrm{pH} \mathrm{1.2)}$ for $2 \mathrm{hrs}$, followed by $\mathrm{pH} 6.8$ phosphate buffer for 4 hrs (with addition of $250 \mathrm{~mL}$ of tribasic phosphate solution $0.215 \mathrm{M}$ ) and then $\mathrm{pH} 7.4$ phosphate buffer for additional 18 hrs. The paddles and the water bath were sealed with PTFE-coated glass cloth adhesive tape (Viking Industrial Products, Keighley, UK) and foil, respectively, and the dissolution assessment was performed in a dark room, to prevent degradation of amlodipine. Each experiment was performed in repetitions of six and samples were manually collected $(4 \mathrm{~mL})$, which was replaced and filtered with an Econofltr $0.2 \mu \mathrm{m}$ syringe filter (Agilent Technologies Ltd., Cheadle, UK). Aliquots were collected at the time points: 0, 0.5, 1, 1.5, 2, 3, 4, 5, 6, 8, 10 , 
$443 \quad 12$ and $24 \mathrm{hrs}$ and analysed by the developed HPLC method previously described. The period of 44424 hours was selected to cover the total transit time of non-disintegrating tablet (PLA based 445 capsule) in the gastrointestinal tract. ${ }^{[55]}$

446 With the assumption that a detectable drug concentration is reached when the capsule wall is 447 completely dissolved, the erosion rate $(\mathrm{mm} / \mathrm{hrs})$ was estimated using the following equation:

448 Erosion rate $=\mathrm{d}(\mathrm{mm}) / \mathrm{t}_{\text {lag }}(\mathrm{hrs})$

449 where (d) is the thickness of the wall, and ( $\left.\mathrm{t}_{\text {lag }}\right)$ is the lag time before the onset of drug release.

450 In silico simulation The absorption profile simulation for each drug was developed using 451 Gastroplus ${ }^{\circledR}$ v9.7 (Simulation Plus, Lancaster, CA, USA). For the 'compound' and 452 'pharmacokinetics' models, input data included experimental data (dissolution profile, 453 permeability and solubility) and data obtained from literature. When precise compound 454 parameters values were not available, parameter estimation was performed by the software. 455 Human physiology under fasted state mode was designated and default values were used.

456 The physicochemical properties and ADME parameters for each drug were obtained from 457 literature (Supporting information, Table S5).

458 Statistical analysis Statistical analysis of the results was done with independent t-test using SPSS 459 software (22.0.2). Differences in the results below the probability level of $p<0.05$ were considered 460 significant. 
[1] C.J. Charlesworth, E. Smit, D.S. Lee, F. Alramadhan, M.C. Odden, J. Gerontol. A. Biol. Sci. Med. Sci. 2015, 70, 989.

[2] B. Guthrie, B. Makubate, V. Hernandez-Santiago, T. Dreischulte, BMC Med, 2015, 13, 15.

[3] E.R. Hajjar, A.C. Cafiero, J.T. Hanlon, Am. J. Geriatr. Pharmacother. 2007, 5, 345.

[4] EHN, European Cardiovascular Disease: Statistics 2017 edition, in: S. Løgstrup (Ed.), Belgium, 2017.

468

[5] NICE, Cardiovascular disease risk assessment and prevention, https://bnf.nice.org.uk/treatment-summary/cardiovascular-disease-risk-assessment-andprevention.html, accessed: 8/2019.

$4712018,252,181$.

[7] S. Assari, M. Bazargan, Pharmacy (Basel), 2019, 7, 14.

[8] S. Leszek, J. Jadwiga, B.-S. Agnieszka, Ars Pharmaceutica, 2016, 57, 137.

[9] A. Atreja, N. Bellam, S.R. Levy, MedGenMed, 2005, 7,4.

[10] PillPack, Pill Pack, https://www.pillpack.com/how-it-works, accessed: 7/2019.

[11] NIHR, My medication passport, http://clahrc-northwestlondon.nihr.ac.uk/resources/mmp, accessed: 7/2019.

[12] R.L. Padilla, S. Byers-Connor, H.L. Lohmam, Occupational Therapy with Elders: Strategies for the Cota., Second ed., Elsevier, USA, 2012.

[13] A.D. Black, J. Car, C. Pagliari, C. Anandan, K. Cresswell, T. Bokun, B. McKinstry, R. Procter, A. Majeed, A. Sheikh, PLoS Med.2011, 8, 1000387.

[14] J.M. Castellano, H. Bueno, V. Fuster, Int. J. Cardiol. 2015, 201, 31027.

[15] S.E. Moulton, G.G. Wallace, J. Control. Release. 2014, 193, 27.

[16] M. Alomari, F.H. Mohamed, A.W. Basit, S. Gaisford, J. Pharm. 2015, 494, 56.

[17] A. Goyanes, F. Fina, A. Martorana, D. Sedough, S. Gaisford, A.W. Basit, Int. J. Pharm. 2017, 527, 21.

[18] K. Ilyes, N.K. Kovacs, A. Balogh, E. Borbas, B. Farkas, T. Casian, G. Marosi, I. Tomuta, Z.K. Nagy, Eur. J. Pharm. Sci. 2019, 129, 110.

[19] B. Arafat, N. Qinna, M. Cieszynska, R.T. Forbes, M.A. Alhnan, Eur. J. Pharm. Biopharm. 2018, 128, 282.

[20] N. Scoutaris, S.A. Ross, D. Douroumis, 3D Printed "Starmix" Drug Loaded Dosage Forms for Paediatric Applications, Pharm. Res. 2018, 35, 17.

[21] M. Sadia, A. Isreb, I. Abbadi, M. Isreb, D. Aziz, A. Selo, P. Timmins, M.A. Alhnan, Eur. J. Pharm. Sci. 2018, 123, 484.

[22] C.I. Gioumouxouzis, A. Baklavaridis, O.L. Katsamenis, C.K. Markopoulou, N. Bouropoulos, D. Tzetzis, D.G. Fatouros, Eur. J. Pharm. Sci. 2018, 120, 40.

[23] T. Tagami, K. Fukushige, E. Ogawa, N. Hayashi, T. Ozeki, Biol. Pharm. Bull. 2017, 40, 357. [24] X. Chai, H. Chai, X. Wang, J. Yang, J. Li, Y. Zhao, W. Cai, T. Tao, X. Xiang, Sci. Rep. 2017, 7, 17.

[25] B. Arafat, M. Wojsz, A. Isreb, R.T. Forbes, M. Isreb, W. Ahmed, T. Arafat, M.A. Alhnan, Eur. J. Pharm. Sci. 2018, 118, 191.

[26] A. Melocchi, F. Parietti, G. Loreti, A. Maroni, A. Gazzaniga, L. Zema, J. Drug Deliv. Sci. Technol. 2015, 30.

[27] D. Smith, Y. Kapoor, A. Hermans, R. Nofsinger, F. Kesisoglou, T.P. Gustafson, A. Procopio, Int. J. Pharm. 2018, 550, 418.

[28] G. Matijašić, M. Gretić, J. Vinčić, A. Poropat, L. Cuculić, T. Rahelić, J. Drug Deliv. Sci. Technol. 2019, 52, 677. 
508 [29] A. Maroni, A. Melocchi, F. Parietti, A. Foppoli, L. Zema, A. Gazzaniga, J. Control. Release. $5092017,268,10$.

510 [30] D.M. Smith, Y. Kapoor, G.R. Klinzing, A.T. Procopio, J. Pharm. 2018, 544, 21.

511 [31] T.C. Okwuosa, C. Soares, V. Gollwitzer, R. Habashy, P. Timmins, M.A. Alhnan, Eur. J. 512 Pharm. Sci. 2018, 118, 134.

513 [32] X.L. Jiang, P. Zhao, J. Barrett, L. Lesko, S. Schmidt, CPT: pharmacometrics \& systems 514 pharmacology, 2018, 2, 80.

515 [33] P.N. Morcos, Y. Cleary, C. Sturm-Pellanda, E. Guerini, M. Abt, M. Donzelli, F. Vazvaei, B. 516 Balas, N. Parrott, L. Yu, J. Clin. Pharmacol. 2018, 58, 1618.

517 [34] M.A. Rahman, A. Hussain, M.S. Hussain, M.A. Mirza, Z. Iqbal, Drug. Dev. Ind. Pharm. $518 \quad \mathbf{2 0 1 3}, 39,1$.

519 [35] S.S. Hong, S.H. Lee, Y.J. Lee, S.J. Chung, M.H. Lee, C.K. Shim, J. Control. Release. 1998, $520 \quad 51,185$.

521 [36] P. Augustijns, M. Brewster, Solvent Systems and Their Selection in Pharmaceutics and 522 Biopharmaceutics, Springer/AAPS Press, New York, 2007.

523 [37] F.H. Falqi, O.A. Bin-Dahman, M. Hussain, M.A. Al-Harthi, Int. J. Polym. Sci. 2018, 10.

524 [38] L.Y. Lim, L.S.C. Wan, Drug. Dev. Ind. Pharm. 1994, 1007.

525 [39] O. Martin, L. Avérous, Polymer. 2001, 42, 6209.

526 [40] R. Eyjolfsson, Drug. Dev. Ind. Pharm. 1998, 24, 797.

527 [41] T.J. DiFeo, J.E. Shuster, Academic Press, Indapamide. In: H. G. Brittain (Ed.) Analytical 528 Profiles of Drug Substances and Excipients. Academic Press, USA, 1994.

529 [42] N. Kulkarni, N. Ranpise, G. Mohan, Trop. J. Pharm. Res. 2015, 14, 575.

530 [43] R. Dahima, A. Pachori, S. Netam, Int. J. Chemtech. Res. 2010, 2.

531 [44] D.P. Ip, J.D. DeMarco, M.A. Brooks, Lisinopril, in: H.G. Brittain (Ed.) Analytical Profiles 532 of Drug Substances and Excipients, Academic Press, 1992, pp. 233-276.

533 [45] D.T. Manallack, Perspect. Medicin. Chem. 2007, 1, 25.

534 [46] M.V. Varma, C.J. Rotter, J. Chupka, K.M. Whalen, D.B. Duignan, B. Feng, J. Litchfield, 535 T.C. Goosen, A.F. El-Kattan, Mol. Pharm. 2011, 8, 1303.

536 [47] C.G. Wilson, N. Washington, Drug Dev. Ind. Pharm. 2008, 14,211.

537 [48] S. Vaddiraju, Y. Wang, L. Qiang, D.J. Burgess, F. Papadimitrakopoulos, Anal. Chem. 2012, $538 \quad 84,8837$.

539 [49] J. Zhao, X. Xu, M. Wang, L. Wang, Dissolution Technol. 2018, 25, 24.

540 [50] Center for Drug Evaluation and Research (CDER), FDA, Size, Shape, and Other Physical

541 Attributes of Generic Tablets and Capsules Guidance for Industry,

542 https://www.fda.gov/media/87344/download, accessed: 03/2020

543 [51] L. Malcolm, Accelerated Predictive Stability (APS), 2018, 287.

544 [52] F. Elisa, A. Angelo, G. Silvia, Int. J. Pharm. 2007, 352, 197.

545 [53] B.C. Pereira, A. Isreb, R.T. Forbes, F. Dores, R. Habashy, J.B. Petit, M.A. Alhnan, E.F. Oga,

546 Eur. J. Pharm. Biopharm. 2019, 135, 94.

547 [54] PubChem, https://pubchem.ncbi.nlm.nih.gov/, accessed: 9/2019.

548 [55] G. Sathyan, S. Hwang, S.K. Gupta, Int. J. Pharm. 2000, 204, 47. 


\section{WILEY-VCH}

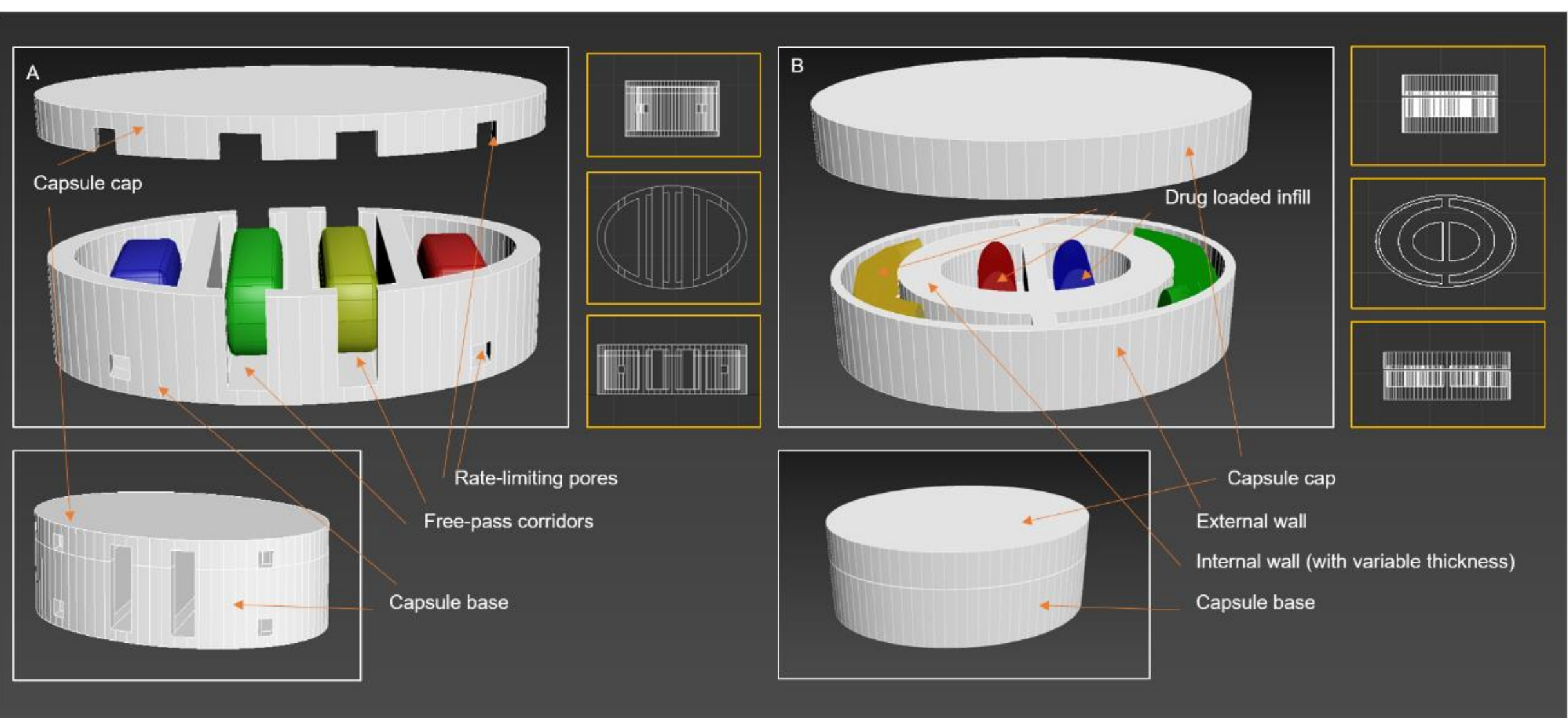

Figure 1 Rendered images of computer-aided design (CAD) (Autodesk 3DS Max) of capsule base and cap of (A) PLA capsules of parallel compartments with free-pass corridors and rate-limiting pores and (B) PVA capsules of concentric compartments design and varying internal wall thicknesses. 


\section{WILEY-VCH}
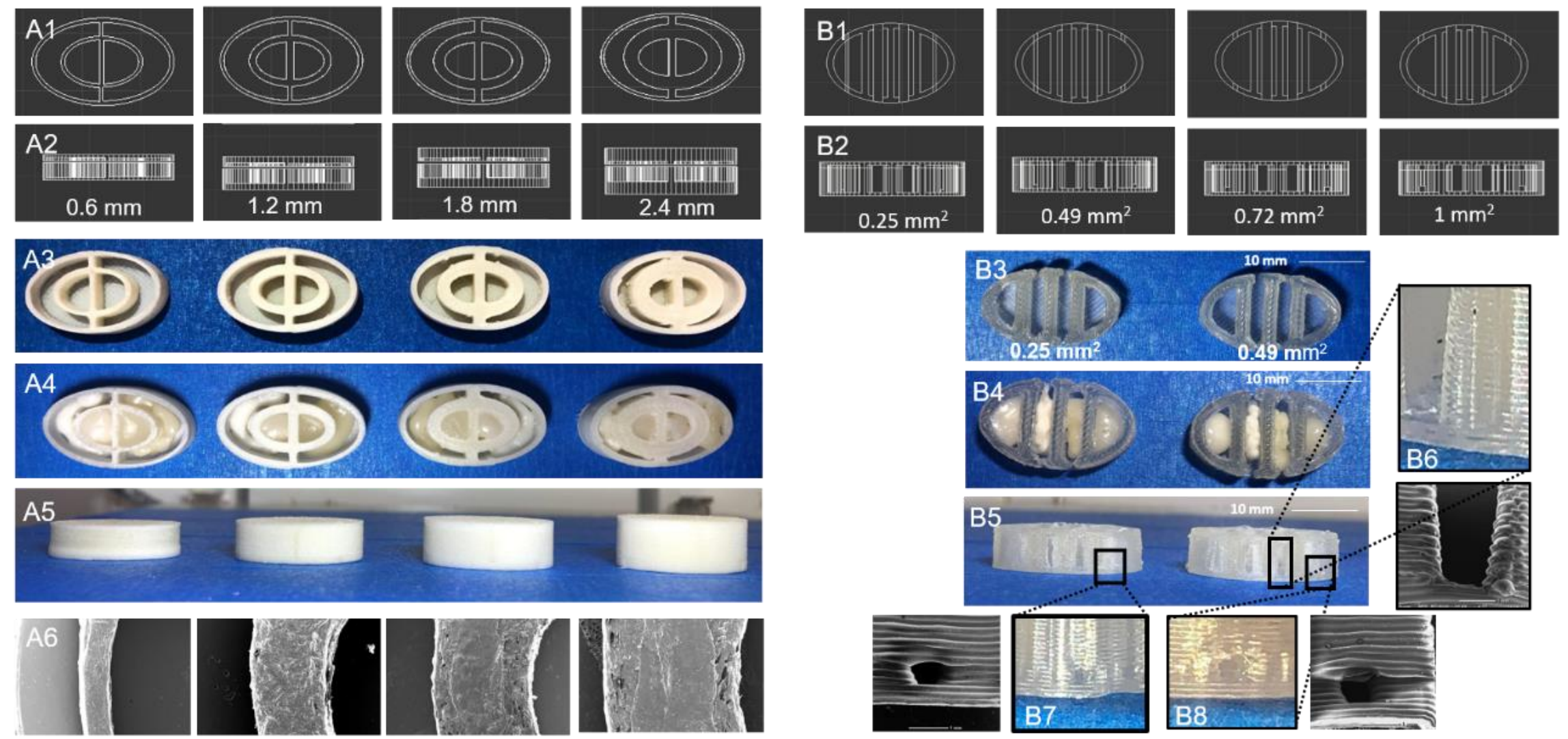

Figure 2 Schematic images of PVA capsules with increased thickness of (A1) inner wall and (A2) base and cap layers. Images of the PVA concentric design capsules (A3) 3D printed base, (A4) capsule filling, (A5) sealed capsules. (A6) SEM images of the inner wall with increased thickness. Images of PLA parallel design capsules (B1) printed base, (B2) capsule filling, (B3) sealed capsules. Detailed images and correspondent SEM pictures of rate-limiting pores with (B4) $0.25 \mathrm{~mm}^{2}$ and (B5) $0.49 \mathrm{~mm}^{2}$ areas and (B6) corridors from PLA capsules. 


\section{WILEY-VCH}

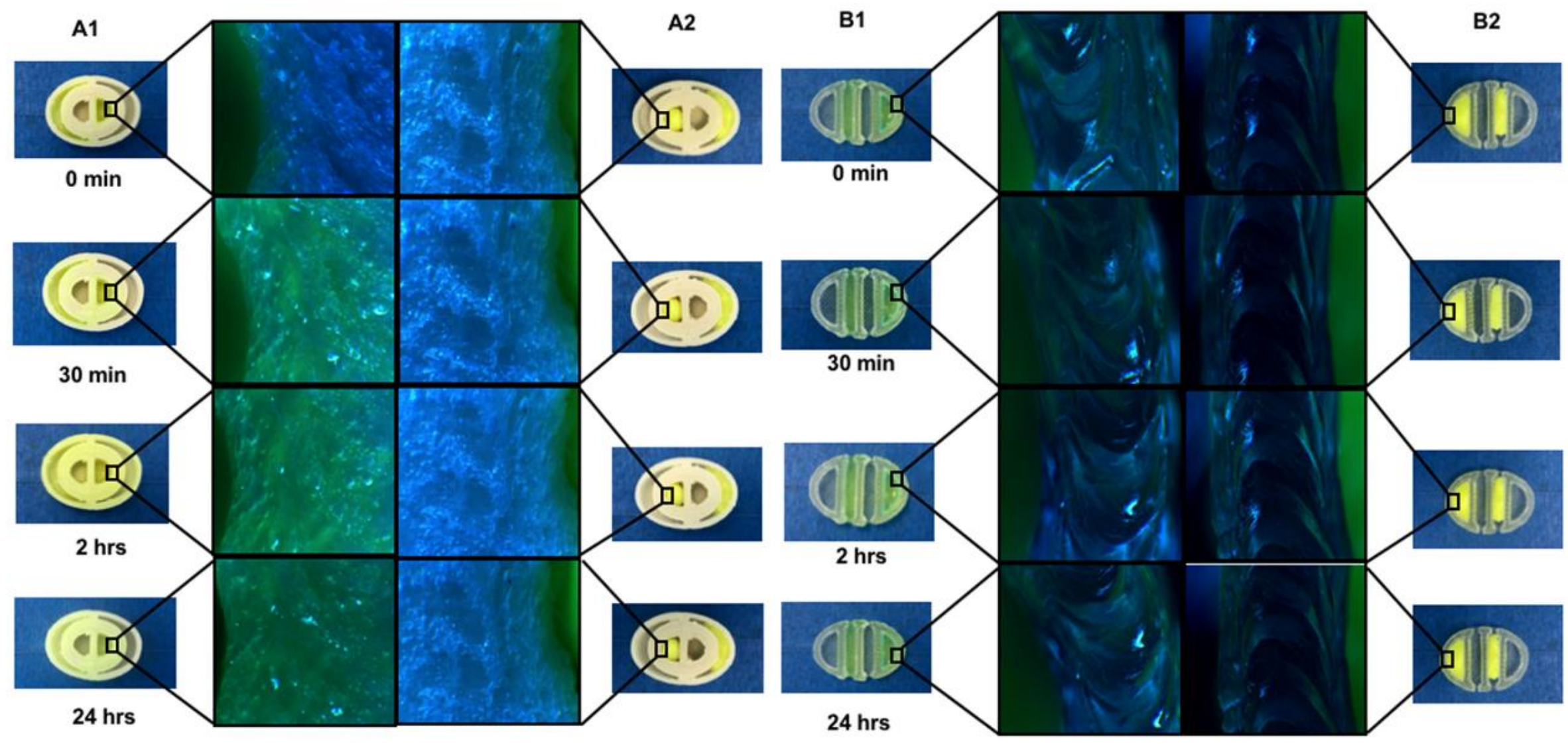

Figure 3 Images of (A1) PVA and (B1) PLA shells with dipyridamole PEG and (A2) PVA and (B2) PLA shells with dipyridamole-loaded capsule filling. 


\section{WILEY-VCH}
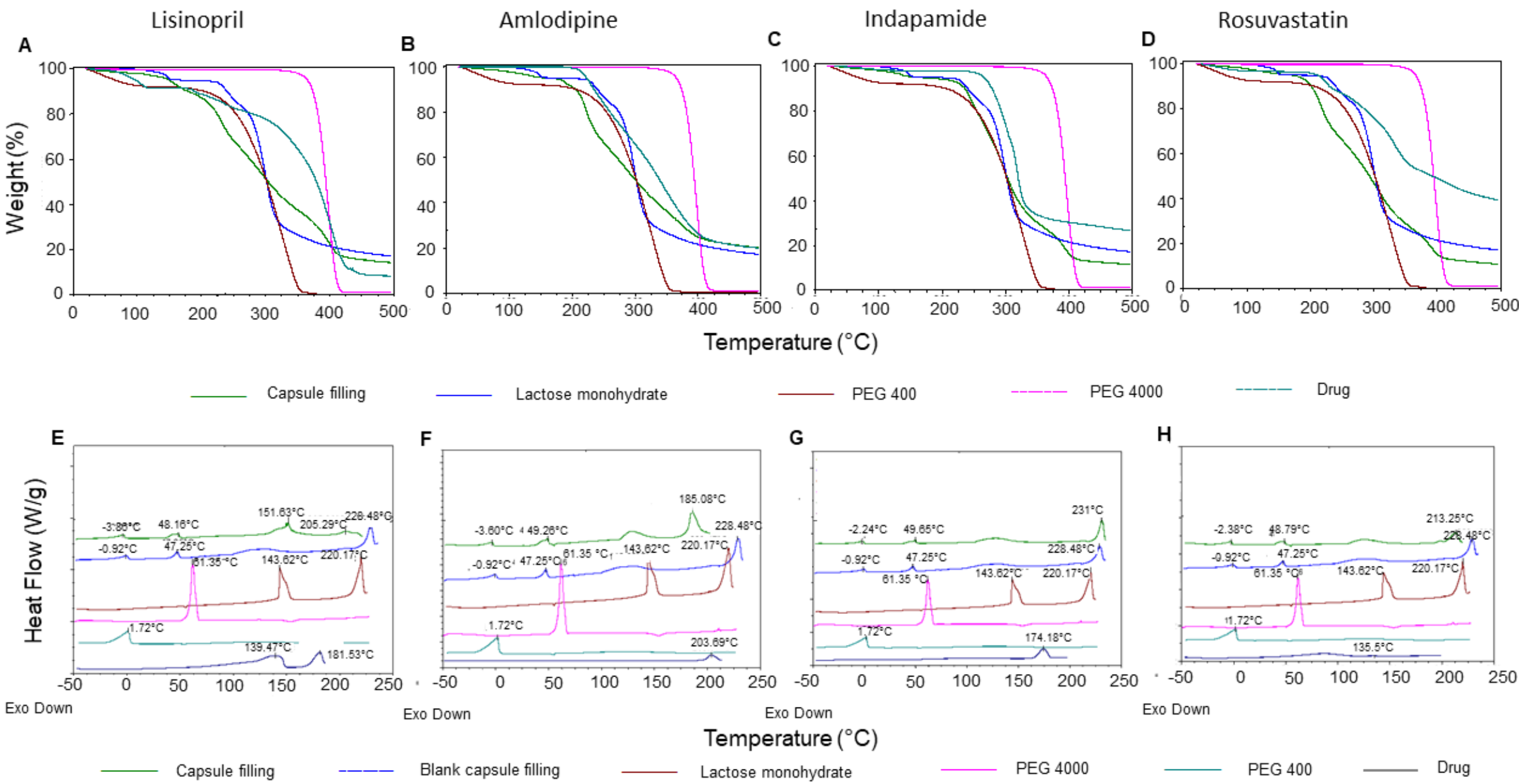

Figure 4 TGA profiles and DSC scans of raw materials and capsule filling of (A/E) lisinopril, (B/F) amlodipine, $(\mathbf{C} / \mathbf{G})$ indapamide and (D/H) rosuvastatin, respectively. 


\section{WILEY-VCH}

A

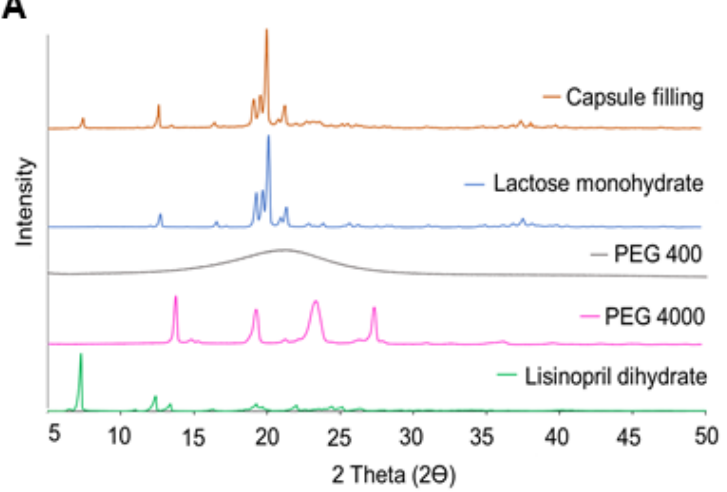

D

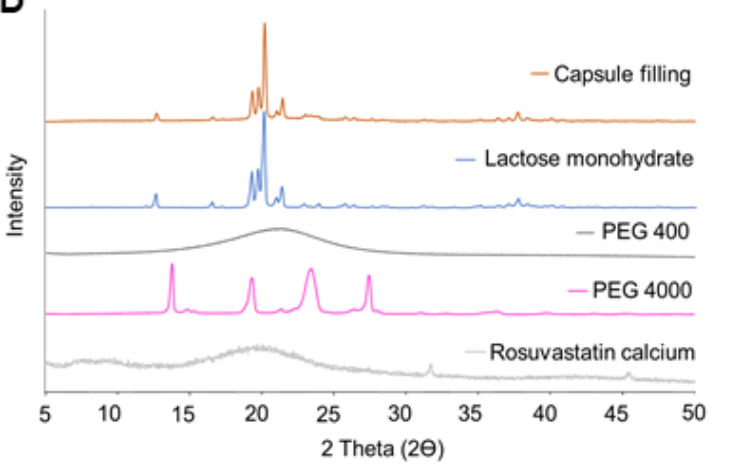

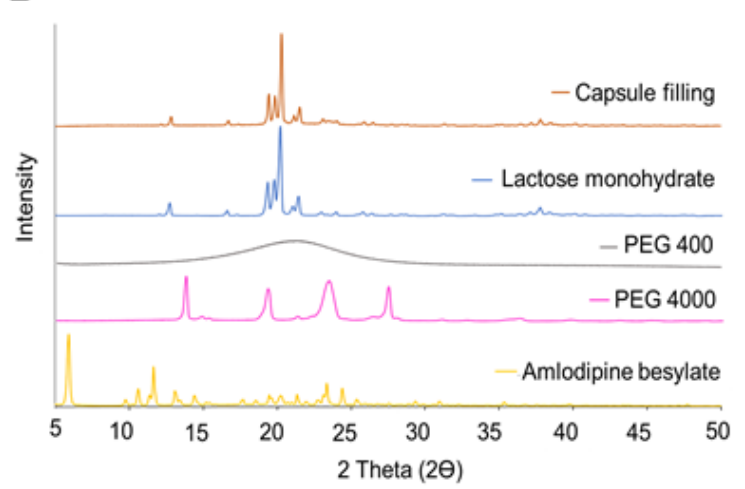

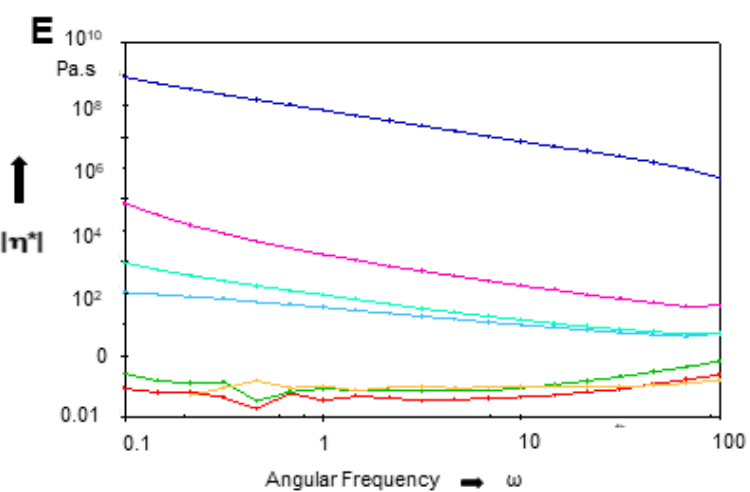

PEG 4000 at $50{ }^{\circ} \mathrm{C}$

- PEG 400 at $50^{\circ} \mathrm{C}$

PEG $400+$ PEG 4000 at $50^{\circ} \mathrm{C}$

PEG $400+$ lisinopril at $50^{\circ} \mathrm{C}$

PEG $400+$ PEG $4000+$ lisinopril at $50^{\circ} \mathrm{C}$

PEG $400+$ PEG $4000+$ lactose at $50^{\circ} \mathrm{C}$

PEG $400+$ PEG $4000+$ lisinopril + lactose at $50^{\circ} \mathrm{C}$
C
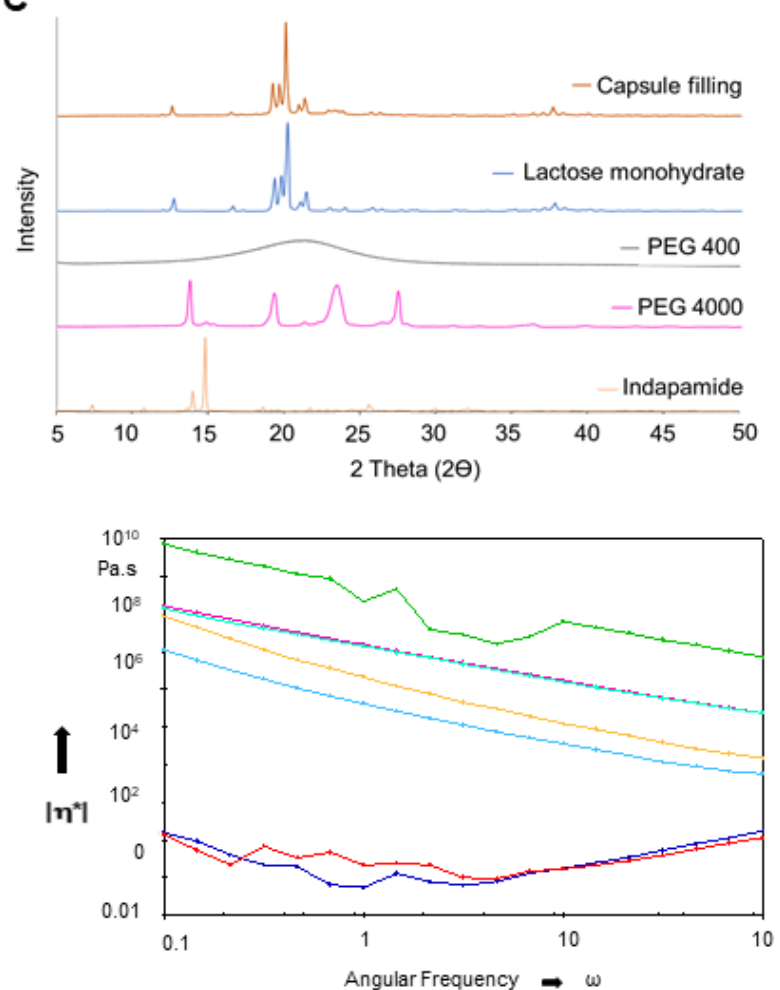

2.- PEG 4000 at $40^{\circ} \mathrm{C}$

PEG 400 at $40^{\circ} \mathrm{C}$

PEG $400+$ PEG 4000 at $40^{\circ} \mathrm{C}$

- PEG $400+$ lisinoptil at $40^{\circ} \mathrm{C}$

- PEG $400+$ PEG $4000+$ lisinopril at $40{ }^{\circ} \mathrm{C}$

PEG $400+$ PEG $4000+$ lactose at $40{ }^{\circ} \mathrm{C}$

PEG $400+$ PEG $4000+$ lisinopril + lactose at $40^{\circ} \mathrm{C}$

Figure 5 Powder XRD patterns of raw materials and capsule filling of (A) lisinopril, (B) amlodipine, (C) indapamide and (D) rosuvastatin. Complex viscosity of PEG 400, PEG 4000 and their mixtures with and without lactose and with lisinopril at (E) $50{ }^{\circ} \mathrm{C}$ and (F) $40{ }^{\circ} \mathrm{C}$. 


\section{WILEY-VCH}
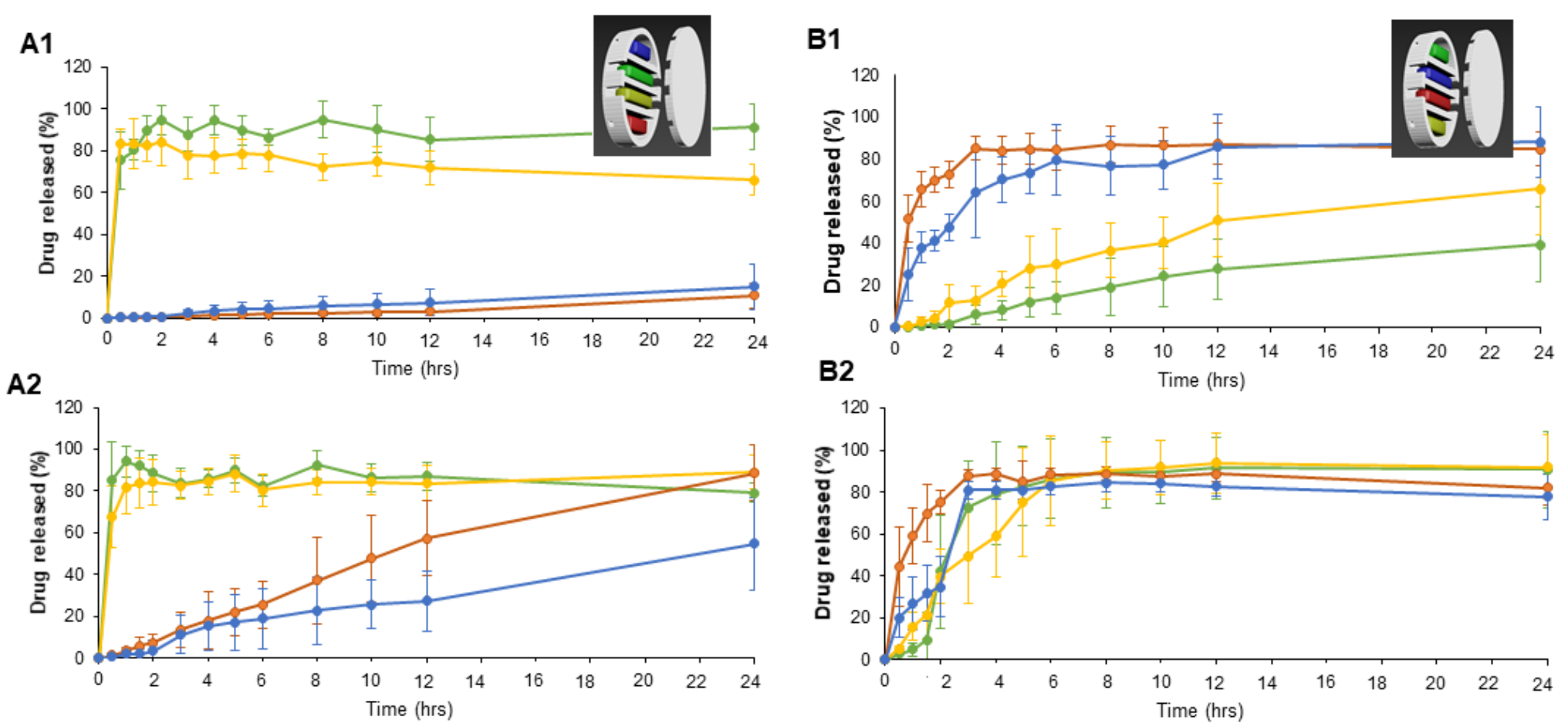

$\rightarrow$ Lisinopril dihydrate

$\ldots$ Amlodipine besylate

$\rightarrow$ Indapamide $\rightarrow$ Rosuvastatin calcium

Figure 6 In vitro drug release of PLA parallel design capsules with (A1 and B1) $0.25 \mathrm{~mm}^{2}$ pores and (A2 and B2) $0.49 \mathrm{~mm}^{2}$ pores (n=6). 


\section{WILEY-VCH}

A1
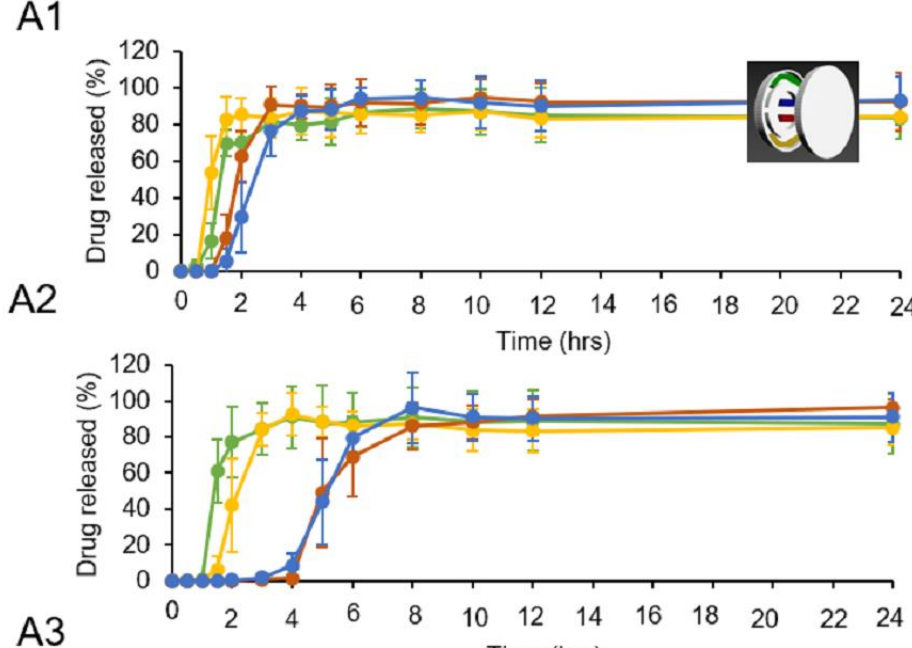

A3

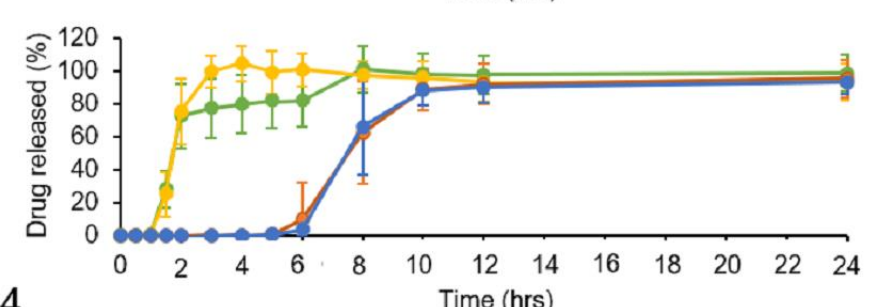

A4

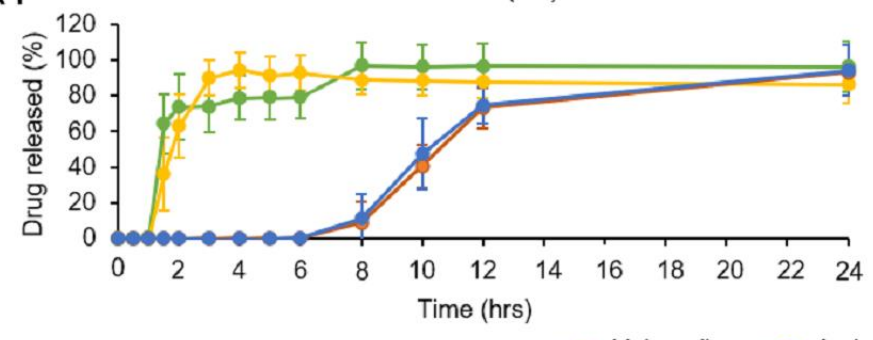

B1
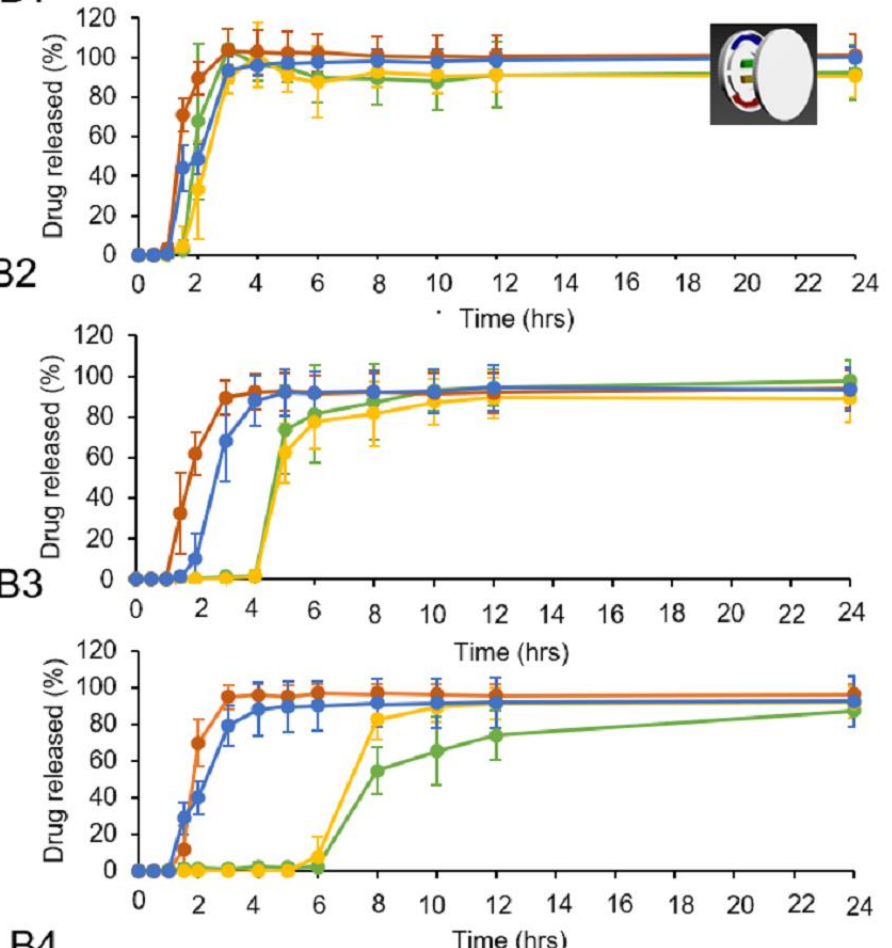

B4

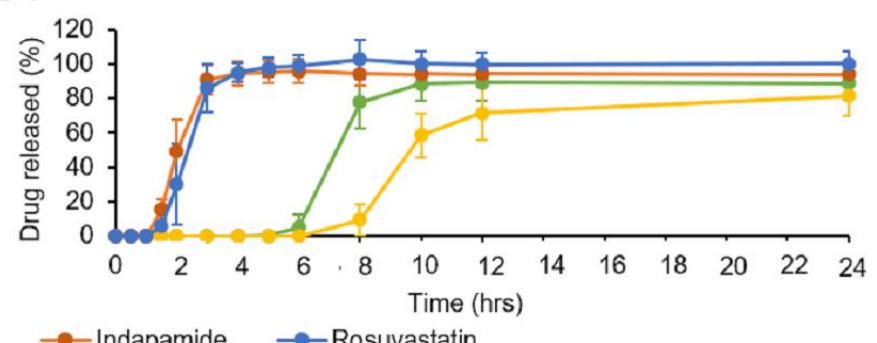

Figure 7 In vitro drug release of PVA concentric design capsules with (A1 and B1) $0.6 \mathrm{~mm}$, (A2 and B2) $1.2 \mathrm{~mm}$, (A3 and B3) $1.8 \mathrm{~mm}$ and (A4 and B4) 2.4 $\mathrm{mm}$ inner wall thickness $(\mathrm{n}=6)$. 


\section{WILEY-VCH}
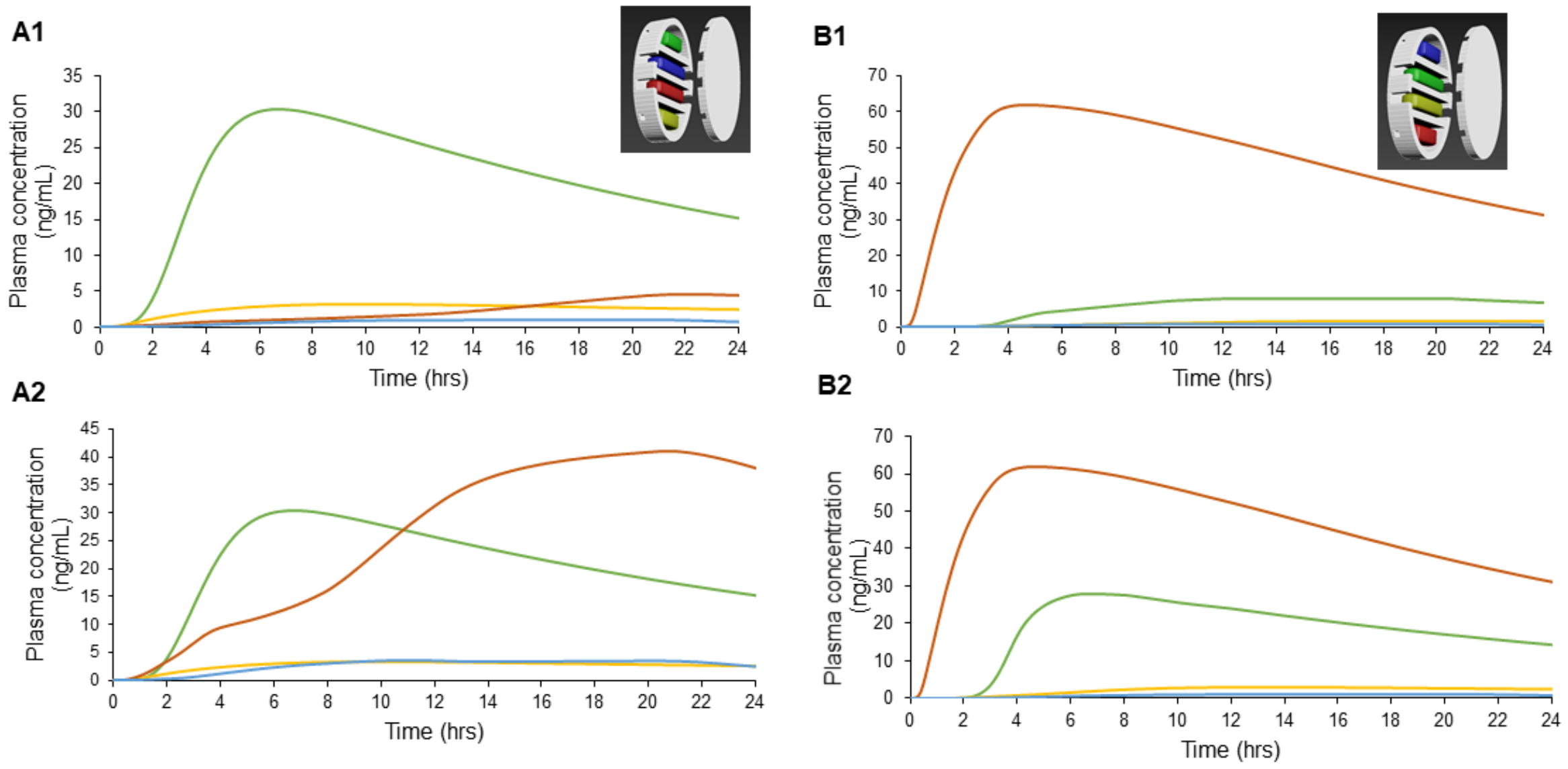

- Lisinopril dihydrate - Amlodipine besylate - Indapamide - Rosuvastatin calcium

Figure 8 Simulated mean plasma profiles of PLA capsules with $0.25 \mathrm{~mm}^{2}$ (A1/B1) and $0.49 \mathrm{~mm}^{2}$ (A2/B2) pores PLA capsules, respectively. 


\section{WILEY-VCH}
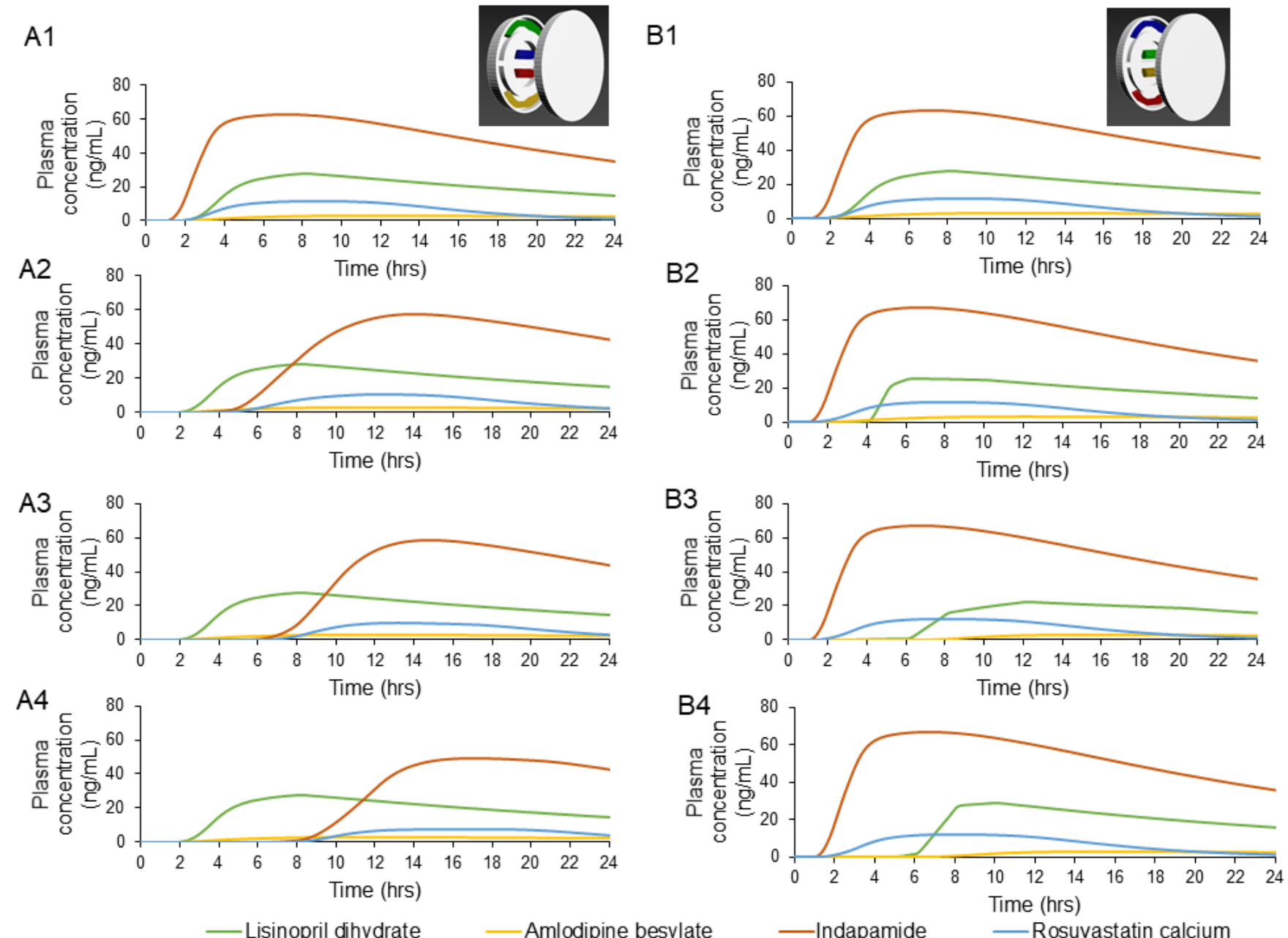

Figure 9 Simulated mean plasma profiles of PVA capsules with $0.6 \mathrm{~mm}$ (A1/B1), $1.2 \mathrm{~mm}(\mathrm{~A} 2 / \mathrm{B} 2), 1.8 \mathrm{~mm}(\mathrm{~A} 3 / \mathrm{B} 3)$ and 2.4 mm (A4/B4) wall thickness. 


\section{WILEY-VCH}

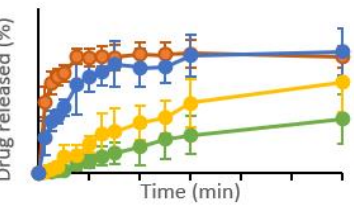

In vitro data

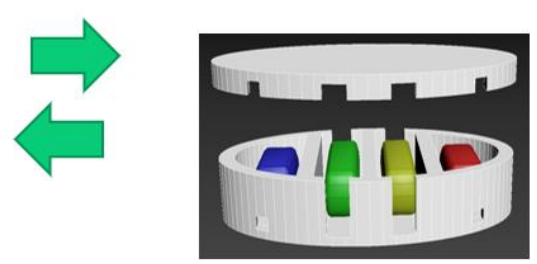

Refined personalised 'polypill' design
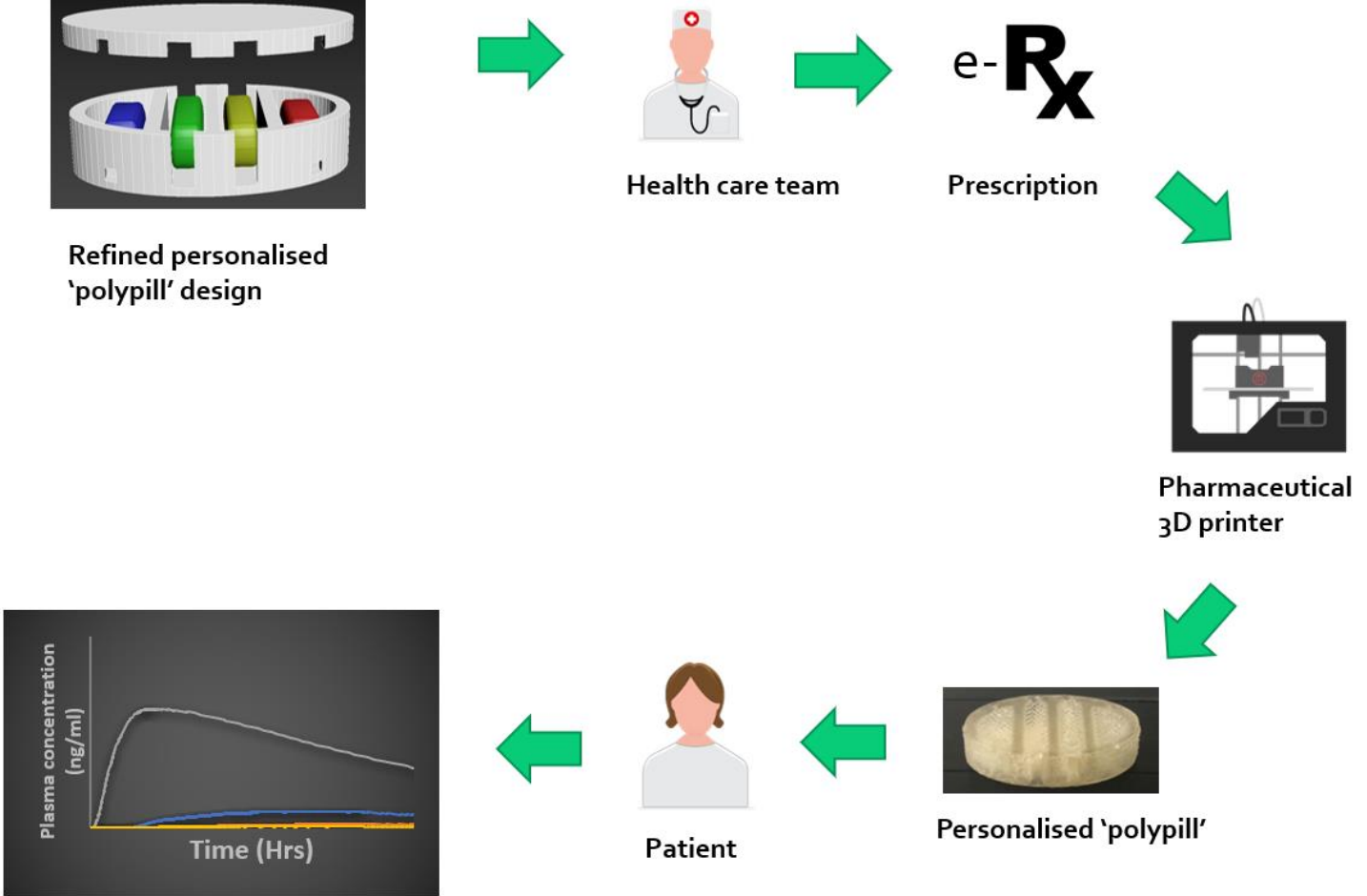

In vivo $\mathrm{PK}$ verification
Health care team

e- $\mathbf{R}_{\mathbf{X}}$

Prescription ${ }_{3}$ D printer

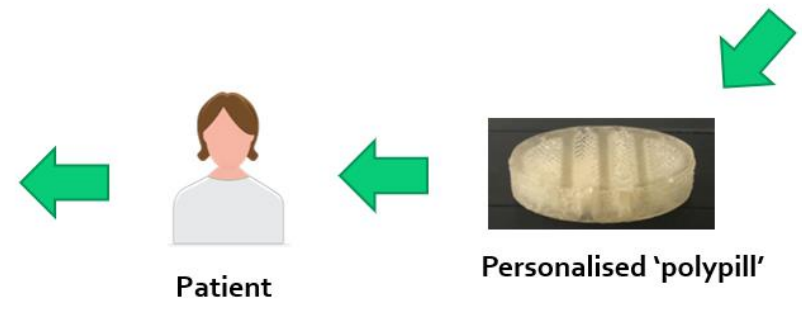

Figure 10 Schematic diagram of future scenario for integrated electronic healthcare system that employ Pharmaceutical 3D printer. The patient's medical information and genomic specifics will be fed in artificial intelligence system, where target PK simulation will be set. Computer software will help to generate an in vitro plasma profile and a tailored 'polypill' design will be built. Healthcare team will approve a corresponding e-prescription and a personalised polypill will be 3D printed and dispensed to the patient. The PK data from patients to improve and maintain target plasma exposure of multiple drugs. The increased number of repeated cycles as well as number participants will improve the accuracy of the system. 


\section{WILEY-VCH}

Table 1. Composition of hot-filled capsule contents.

\begin{tabular}{|c|c|c|c|c|c|c|c|}
\hline \multirow[t]{2}{*}{ Drug-loaded capsule filling } & \multicolumn{7}{|c|}{ Ingredients $(w / w \%)$} \\
\hline & $\begin{array}{l}\text { Lisinopril } \\
\text { dihydrate }\end{array}$ & $\begin{array}{l}\text { Amlodipine } \\
\text { besylate }\end{array}$ & Indapamide & $\begin{array}{l}\text { Rosuvastatin } \\
\text { calcium }\end{array}$ & PEG 4000 & PEG 400 & $\begin{array}{l}\text { Lactose } \\
\text { monohydrate }\end{array}$ \\
\hline Lisinopril dihydrate & $10 \%$ & - & - & - & $10 \%$ & $30 \%$ & $50 \%$ \\
\hline Amlodipine besylate & - & $5 \%$ & - & - & $10 \%$ & $30 \%$ & $55 \%$ \\
\hline Indapamide & - & - & $2.5 \%$ & - & $10 \%$ & $30 \%$ & $57.5 \%$ \\
\hline Rosuvastatin calcium & - & - & - & $10 \%$ & $10 \%$ & $30 \%$ & $50 \%$ \\
\hline
\end{tabular}

Table 2. Solubility parameters in $\mathrm{MPa}^{1 / 2}$ and components.

\begin{tabular}{|c|c|c|c|c|}
\hline \multirow[t]{2}{*}{ Compound } & \multicolumn{2}{|c|}{ Solubility parameters } & \multirow[b]{2}{*}{$\delta \mathbf{H}$} & \multirow[b]{2}{*}{ HSP } \\
\hline & $\delta \mathrm{D}$ & $\delta \mathbf{P}$ & & \\
\hline Rosuvastatin & 18.7 & 11.8 & 10 & 24.3 \\
\hline Lisinopril & 17.1 & 8.2 & 9.1 & 21 \\
\hline Indapamide & 21.6 & 18.9 & 9.6 & 30.2 \\
\hline Amlodipine & 18 & 4.3 & 7.2 & 19.8 \\
\hline PEG & 19.5 & 13.1 & 20.3 & 31 \\
\hline
\end{tabular}

